\title{
Efficient, chemoselective synthesis of immunomicelles using single-domain antibodies with a C-terminal thioester Sanne WA Reulen ${ }^{1}$, Ingrid van Baal ${ }^{1}$, Jos MH Raats ${ }^{2,3}$ and Maarten Merkx ${ }^{* 1}$
}

\begin{abstract}
Address: ${ }^{1}$ Laboratory of Chemical Biology, Department of Biomedical Engineering, Eindhoven University of Technology, P.O. Box 513, 5600 MB Eindhoven, the Netherlands, ${ }^{2}$ Department of Biomolecular Chemistry, Radboud University Nijmegen, P.O. Box 91016500 HB Nijmegen, the Netherlands and ${ }^{3}$ ModiQuest B.V., Heijendaalseweg 135, 6525 AJ, Nijmegen, the Netherlands
\end{abstract}

Email: Sanne WA Reulen - s.w.a.reulen@tue.nl; Ingrid van Baal - ingrid.vanbaal@organon.com; Jos MH Raats - jraats@modiquestresearch.com; Maarten Merkx* -m.merkx@tue.nl

* Corresponding author

Published: 20 July 2009

BMC Biotechnology 2009, 9:66 doi:10.1 186/1472-6750-9-66

Received: 15 April 2009

Accepted: 20 July 2009

This article is available from: http://www.biomedcentral.com/I472-6750/9/66

(C) 2009 Reulen et al; licensee BioMed Central Ltd.

This is an Open Access article distributed under the terms of the Creative Commons Attribution License (http://creativecommons.org/licenses/by/2.0), which permits unrestricted use, distribution, and reproduction in any medium, provided the original work is properly cited.

\begin{abstract}
Background: Classical bioconjugation strategies for generating antibody-functionalized nanoparticles are non-specific and typically result in heterogeneous compounds that can be compromised in activity. Expression systems based on self-cleavable intein domains allow the generation of recombinant proteins with a $\mathrm{C}$-terminal thioester, providing a unique handle for sitespecific conjugation using native chemical ligation (NCL). However, current methods to generate antibody fragments with $\mathrm{C}$-terminal thioesters require cumbersome refolding procedures, effectively preventing application of $\mathrm{NCL}$ for antibody-mediated targeting and molecular imaging.

Results: Targeting to the periplasm of $E$. coli allowed efficient production of correctly-folded single-domain antibody (sdAb)-intein fusions proteins. On column purification and 2mercapthoethanesulfonic acid (MESNA)-induced cleavage yielded single-domain antibodies with a reactive C-terminal MESNA thioester in good yields. These thioester-functionalized single-domain antibodies allowed synthesis of immunomicelles via native chemical ligation in a single step.

Conclusion: A novel procedure was developed to obtain soluble, well-folded single-domain antibodies with reactive $\mathrm{C}$-terminal thioesters in good yields. These proteins are promising building blocks for the chemoselective functionalization via NCL of a broad range of nanoparticle scaffolds, including micelles, liposomes and dendrimers.
\end{abstract}

\section{Background}

The ability to raise antibodies with high affinity and specificity to almost any biomolecular target has made antibodies essential components in many biomedical fields, both in diagnostics and in the active targeting of drugs and contrast agents for molecular imaging [1]. For many of these applications there has been a drive to move towards smaller antibody formats, both to allow efficient recombinant production in E. coli and to potentially avoid unwanted immunogenic problems [2]. The ability to express these smaller antibody fragments in E. coli has also allowed the application of phage display approaches to allow in vitro screening of large libraries of antibody fragments. Nowadays, a wide range of smaller antibody formats are available including monovalent antibody fragments (Fab), single-chain antibody fragments $(\mathrm{scFv})$, and single-domain antibodies (sdAb) [3]. The latter, which are sometimes also referred to as nanobodies, are 
derived from heavy-chain-only antibodies that have been found in camels, dromedaries, llamas and sharks $[3,4]$. Single-domain antibodies are the smallest antibody fragments available to date and have unique features including high solubility and thermal stability [4].

Current methods for bioconjugation of antibody fragments are non-specific and usually rely on amine and cysteine functionalities present on the protein surface [5]. This lack of control over the conjugation reaction gives rise to heterogeneous protein-nanoparticles. Moreover, the smaller size of single-domain antibodies compared to full size antibodies significantly increases the risk of affecting key residues near the antigen binding site when using non-specific conjugation strategies. In recent years several bioorthogonal ligation reactions that were originally developed in peptide chemistry have been applied for chemoselective protein functionalization of nanoparticles and chip surfaces [6-14]. Two examples of antibody conjugation using oxime chemistry were recently reported that take advantage of novel methods to selectively oxidize the N-terminus of antibodies or introduce genetically-encoded aldehyde tags at any position in the antibody sequence $[15,16]$. While promising, the applicability of oxime chemistry is still hampered by the incomplete introduction of ketone functionalities and the inability to use $\mathrm{N}$-terminal acetylated proteins $[17,18]$. We and others have therefore explored the use of native chemical ligation (NCL) as an alternative chemoselective conjugation reaction, demonstrating its potential for the ligation of proteins to chip surfaces, dendrimers, supported lipid bilayers, micelles and liposomes $[6,11,12,19$ 23]. Native chemical ligation is a chemoselective reaction under aqueous conditions between a C-terminal thioester and an N-terminal cysteine yielding a native peptide bond [24]. Site-specific coupling via NCL was made possible by the development of expression systems with self-cleavable intein domains to generate recombinant proteins with Cterminal thioesters [25].

Intein fusion proteins are normally expressed in the cytoplasm of $E$. coli, a reducing environment that prevents the proper formation of disulfide bonds that are essential for antibody stability. In vitro refolding of scFv-intein fusion proteins followed by on-column NCL has been reported [26], but the requirement to perform NCL on the column limits the applicability of this method. We recently reported a refolding procedure based on the redox couple sodium 2-mercaptoethanesulfonate (MESNA)/sodium 2,2-dithio-bis(ethanesulfonate) (diMESNA) to generate disulfide-containing proteins with a C-terminal MESNA thioester [27]. However, also for this method the requirement to do in-vitro refolding presents an important practical limitation. Here, we present an efficient strategy to obtain well-folded single-domain antibodies with a reac- tive C-terminal thioester by targeting the intein fusion protein to the periplasm of E. coli. Targeting antibody fragments to the oxidizing environment of the bacterial periplasm is known to increase the amount of active antibody fragments by allowing proper disulfide bond formation. Following this new procedure single-domain antibodies with C-terminal thioesters are obtained that can be directly coupled to cysteine-functionalized micelles to generate immunomicelles via native chemical ligation.

\section{Results and discussion \\ Production of single-domain antibodies with a C-terminal thioester}

Our approach, schematically depicted in Figure 1, was tested using a llama single-domain antibody obtained from screening a phage display library against glutathione-S from Schistosoma japonicum. The DNA sequence encoding for this antibody domain (sdAb-aGST) was provided in the pHENIX vector which contains an $\mathrm{N}$-terminal sequence encoding a periplasmic leader sequence (pelB) and C-terminally a vesicular stomatitis virus (VSV-G) tag for detection purposes (see Additional file 1) [28]. The pelB leader sequence was used to target the protein to the oxidizing environment of the periplasm, because the sdAb-aGST protein contains a conserved disulfide bond that is known to be important for the stability of these single domain antibodies [29]. Since transport of the fusion protein to the periplasm could be dependent on the nature of the intein, we tested two commercially available intein expression vectors, pTXB1 and pTYB1 (NEB), that differ in the nature of the intein domain. The target gene was cloned at the $\mathrm{N}$-terminus of the inteins while a chitinbinding domain (CBD) was present at the C-terminus of the intein for purification purposes. Both expression vectors were transformed into E. coli BL21 (DE3) and expression was assayed under a variety of conditions. SDS-PAGE analysis showed that expression using the pTXB1 vector allowed efficient transport of the intein fusion protein to the periplasm of $E$. coli, as evidenced by a band of $45 \mathrm{kDa}$ in the periplasmic fraction (Figure 2). In contrast, expression of the single-domain antibody using the PTYB1 vector resulted in accumulation of the fusion protein as an insoluble aggregate in the cytoplasm of E. coli (not shown).

Figure 2 shows the purification of the MESNA thioester of sdAb-aGST (sdAb-aGST-MESNA) starting form the periplasmic fraction containing the sdAb-aGST-intein-CBD fusion protein. Upon loading the periplasmic fraction on a chitin column the sdAb-aGST-intein-CBD fusion protein binds to the chitin resin. The single-domain antibody with a C-terminal MESNA thioester was eluted from the chitin column after overnight incubation with the thiol MESNA. Yields for thioester terminated single-domain antibodies varied between $2-5 \mathrm{mg} / \mathrm{L}$, which compares 

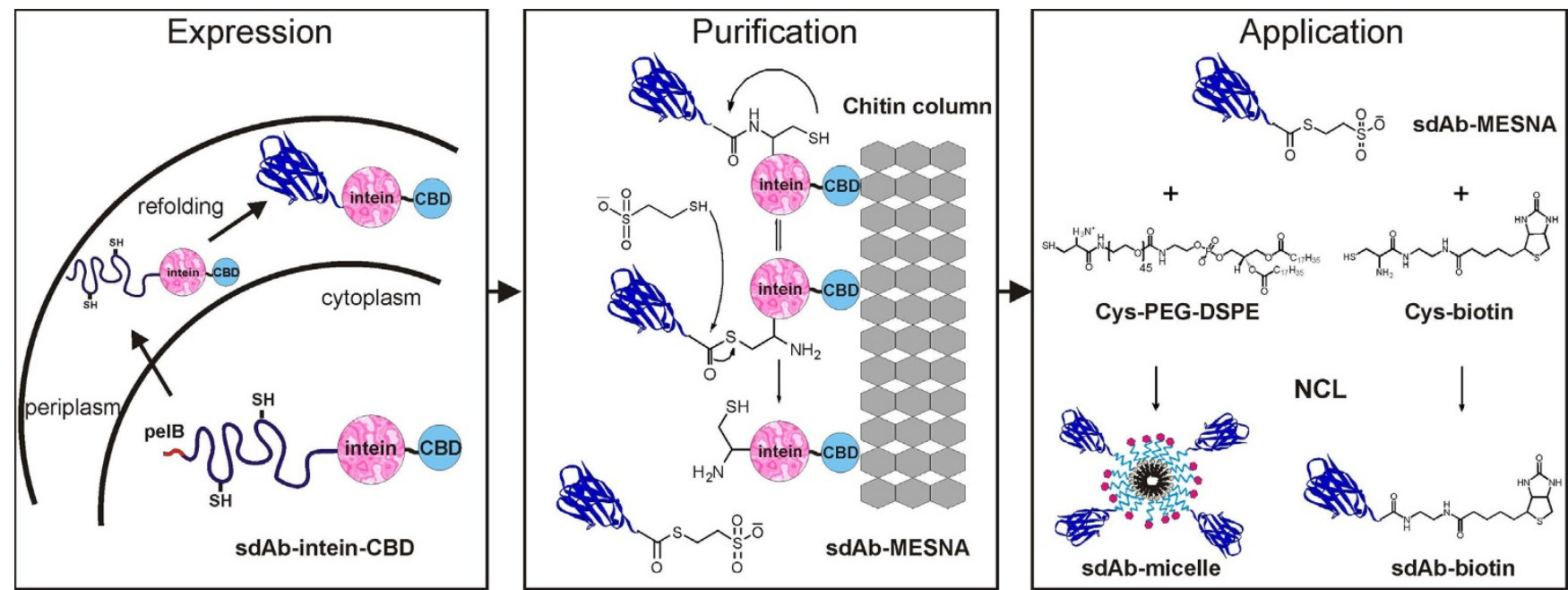

Figure I

Flow chart showing the approach explored in this work. Introduction of a pelB leader sequence targets the sdAbintein-CBD fusion protein to the periplasm, where the presence of disulfide isomerases and an oxidizing environment ensure proper folding and disulfide bond formation of the antibody domain. The chitin binding domain (CBD) allows single-step purification of the fusion protein from the periplasm, where after on-column treatment with MESNA results in intein-mediated cleavage and the formation of single-domain antibody with a reactive C-terminal thioester, which can then be directly applied in subsequent native chemical ligation reactions.

favorably with the $0.1-6 \mathrm{mg} / \mathrm{L}$ yields typically reported for single-domain antibodies via periplasmic expression in E. coli [30]. Since SDS-PAGE analysis showed the presence of two bands of slightly different molecular weight around $18 \mathrm{kDa}$, we performed LC-MS analysis to characterize the obtained proteins (Figure 2B). The main peak at 5.5 min contained sdAb-aGST-MESNA with the pelB leader attached (pelB). This peak also contained sdAbaGST-MESNA with the first amino acid of the pelB leader removed (pelB $\Delta 1)$. The minor peak at 5 min contained two sdAb-aGST-MESNA protein species with the first 14 and 15 amino acids of the pelB leader removed. The double band visible on the SDS-PAGE gel thus corresponds to multiple species of sdAb-aGST, all of which contain a Cterminal MESNA thioester. Addition of protease inhibitors during the purification procedure could not prevent this heterogeneous $\mathrm{N}$-terminal processing. Similar incomplete pelB removal was observed before in E. coli BL21(DE3) strains and has been suggested to be due to the inability of its amino peptidase to efficiently cleave the pelB leader peptide [31]. The minor band observed on the SDS-PAGE gel around $70 \mathrm{kDa}$ was identified using LC-MS as DnaK, a molecular chaperone protein that prevents aggregation of misfolded proteins in E. coli.

The sdAb-aGST protein contains a single disulfide bond that has previously been shown to play an essential role in the stability of these single-domain antibodies. To establish whether the reducing conditions used during MESNA cleavage affected the sdAb-aGST-MESNA produced in this manner, its interaction with GST was studied using Surface Plasmon Resonance (SPR). Initial attempts to immobilize the sdAb-aGST-MESNA to the CM5 Biacore chip using a standard amine coupling procedure resulted in a complete loss of GST binding capacity, suggesting that this classical amine coupling affects residues critical for antigen binding. The sdAb-aGST-MESNA protein contains 11 lysine residues, two of which are indeed located near the antigen binding site. To exclude antibody deactivation the assay was reversed and GST was immobilized on the CM5 chip. Figure 3A shows a clear binding response of the sdAb-aGST-MESNA to GST with an apparent dissociation constant of $120 \mathrm{nM}$. This number is in good agreement with results from an ELISA assay, which showed a dissociation constant of $80 \mathrm{nM}$ (Figure 3B). The observed dissociation constants for the sdAb-aGST are similar to those reported for other single-domain antibodies [32]. In addition, SPR analysis of sdAb-aGST-MESNA after NCL with cysteine (sdAb-aGST-Cys) showed binding behavior that was similar to that of untreated sdAb-aGST (see Additional file 1). So while we cannot exclude at this time that the disulfide bond becomes transiently reduced during MESNA treatment or NCL, these procedures did not irreversibly affect the functionality of sdAb-GST.

\section{Preparation of immunomicelles with single-domain antibodies using NCL}

To test the performance of sdAb-aGST-MESNA in NCL reactions, we first assessed its reactivity towards cysteinefunctionalized biotin. Ligation of this small molecule can 
A

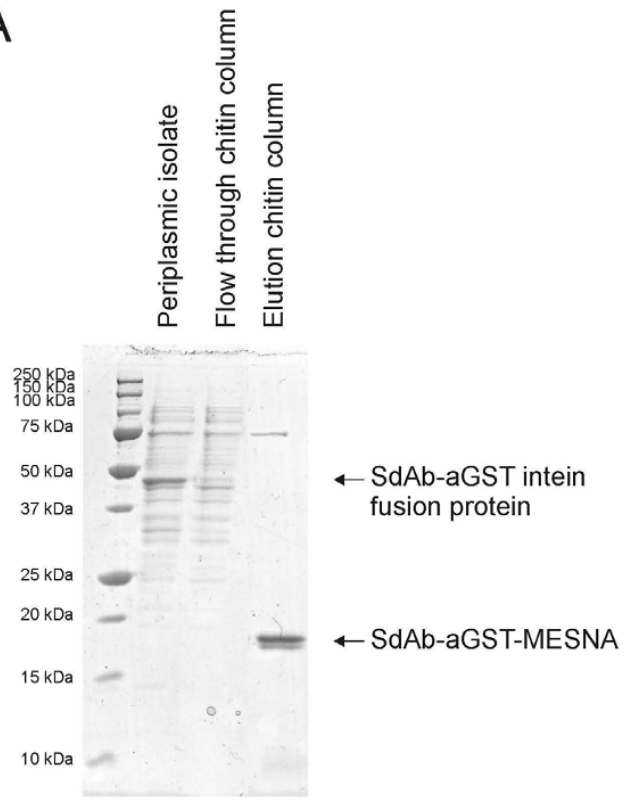

B
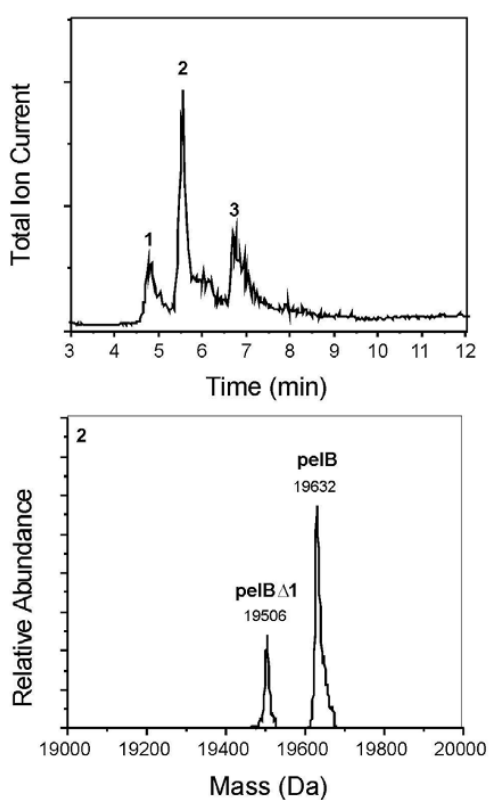
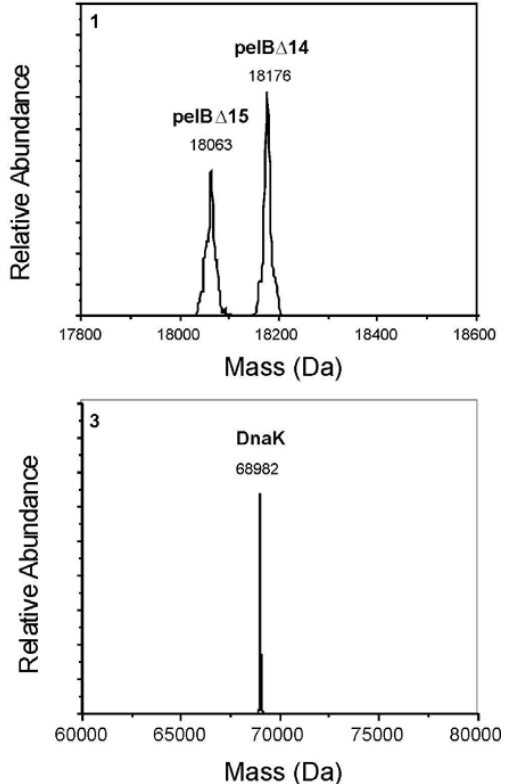

Figure 2

Characterization of the single-domain antibody purification using SDS-PAGE and LC-MS. (A) Expression and purification of the sdAb-aGST as intein fusion protein and subsequent generation of the C-terminal MESNA thioester via chitin affinity chromatography and intein mediated cleavage. (B) LC-MS analysis of the elution fraction of the chitin column. Top left panel: chromatogram; Top right and bottom panels: deconvoluted mass spectra of peaks I, 2 and 3. (pelB: sdAb-aGST-MESNA with pelB leader attached (calcd. mass $19632 \mathrm{Da}$ );pelB $\Delta \mathbf{I}$ : sdAb-aGST-MESNA with the first amino acid of the pelB leader removed (calcd. mass 1950I Da); pelB $\triangle$ I4: sdAb-aGST-MESNA with the first I4 amino acid of the pelB leader removed (calcd. mass $18175 \mathrm{Da}$ ); pelB $\triangle 1$ 5: sdAb-aGST-MESNA with the first 15 amino acid of the pelB leader removed (calcd. mass I $8062 \mathrm{Da}$ ); DnaK (calc. mass $68983 \mathrm{Da})$ ).

A

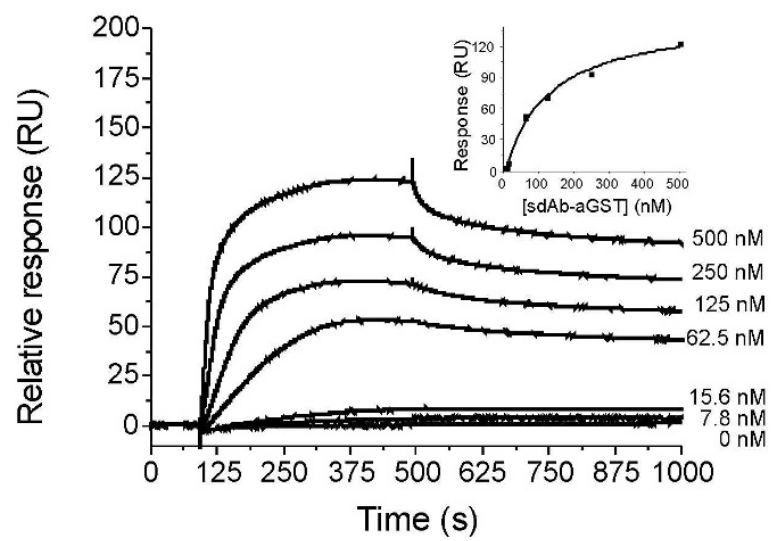

B

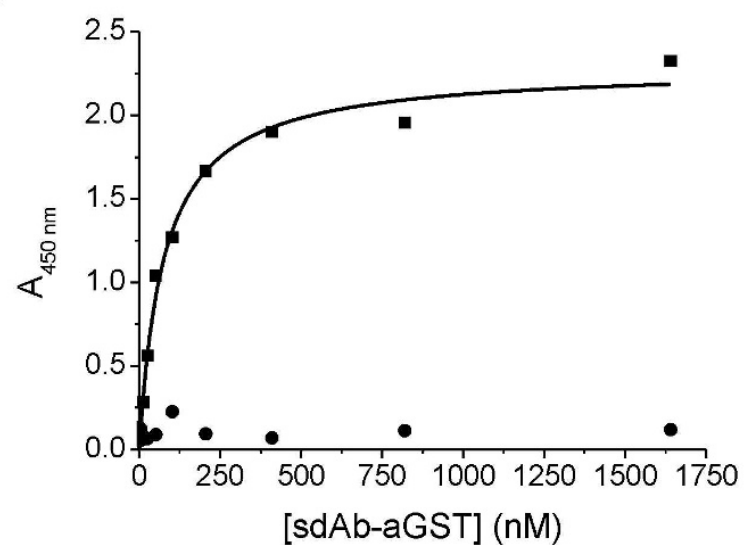

Figure 3

The binding of the sdAb-aGST-MESNA to GST assayed with SPR and ELISA. (A) SPR analysis of sdAb-aGSTMESNA binding to GST. Insert: steady state responses were plotted against the concentration. The line represents a fit to a one-site binding model using a $K_{D}$ of I $16 \mathrm{nM}$. (B) ELISA measurement of binding of sdAb-aGST to GST (square) fitted with a one-site binding model using a $K_{\mathrm{D}}$ of $77 \mathrm{nM}$ and BSA (circle). 
be conveniently monitored using LC-MS. In addition, single-domain antibodies with C-terminal biotin groups are attractive for use in combination with the many streptavidin-modified compounds that are now commercially available. Figure 4 shows the LC-MS analysis of the product obtained after reaction of sdAb-aGST-MESNA with an excess of cysteine-functionalized biotin overnight at room temperature. Again two peaks appear in the chromatogram corresponding to sdAb-aGST with various fragments of the pelB leader sequence still attached. All peaks correspond to biotinylated forms of sdAb-aGST, with the exception of a minor peak at 19635 Da corresponding to a small amount of unreacted sdAb-aGST-MESNA.

Having established the essentially complete biotinylation of sdAb-aGST-MESNA, we next used the sdAb-aGSTMESNA to prepare immunomicelles [22,23]. Pegylated phospholipids such as PEG2000-DSPE are known to form relatively stable micelles with a critical micelle concentration (CMC) of $\sim 5 \mu \mathrm{M}$, forming micelles with a diameter of $13 \mathrm{~nm}$ and approximately 90 lipids per micelle [33]. By attaching cysteine-functionalities at the end of the PEGchain (Cys-PEG2000-DSPE) we recently showed that these micelles can be readily functionalized with up to 20 copies of the collagen binding protein CNA35 equipped with a C-terminal thioester. Here we used the same procedure to prepare micelles functionalized with sdAb-aGST. Micelles were prepared by mixing cysteine-functionalized phospholipids (Cys-PEG2000-DSPE) and rhodamine phospholipids in a 40:1 ratio, followed by addition of sdAb-aGST-MESNA in a 1:11 protein-lipid ratio. SDSPAGE analysis showed essentially complete conversion to the lipidated form after overnight incubation with $50 \mathrm{mM}$ 4-(carboxylmethyl) thiophenol (MPAA) (Figure 5A). Based on the aggregation number of 90 lipids per micelle and the full conversion of the sdAb-aGST to the lipidated form, one can calculate that the micelles contained on average eight sdAb-aGST proteins and two rhodamines. A solid-phase binding assay shows specific binding of the sdAb-aGST functionalized micelles to GST with half maximal binding at $14 \mu \mathrm{M}$ PEG2000-DSPE. Since no binding was observed for non-functionalized micelles, and because the rhodamine-lipid is associated with the micelle via non-covalent interactions, this assay provides direct evidence for the specific binding of intact immunomicelles. It is important to note that the apparent dissociation constant of $\sim 14 \mu \mathrm{M}$ is based on the lipid concentration and reflects the stability of the micelles and not the intrinsic affinity of the sdAb domains attached to the micelles. A similar phenomenon was observed previously for the binding of CNA35-functionalized micelles to collagen, which also showed half maximal binding at a lipid concentration of $\sim 10 \mu \mathrm{M}$, despite the fact that CNA35 by itself binds collagen with $0.5 \mu \mathrm{M}$ affinity [23].
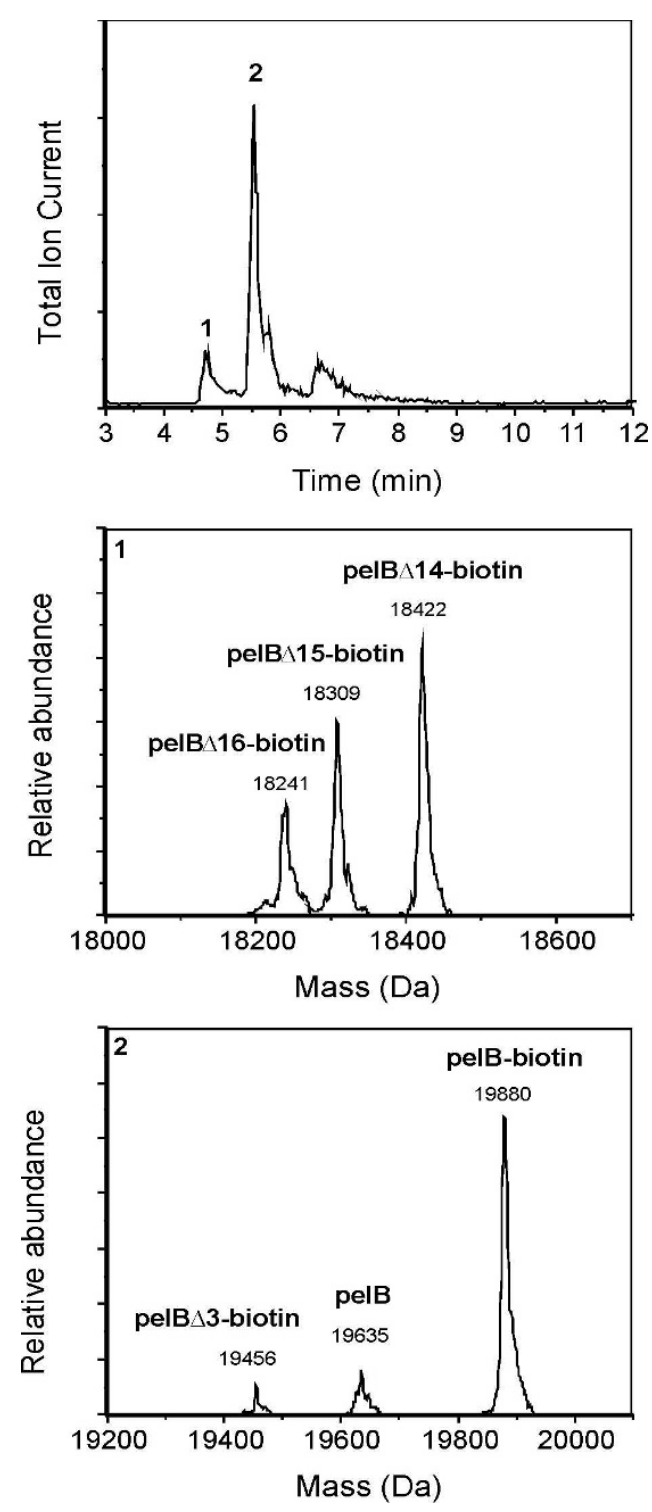

\section{Figure 4}

Chromatogram and deconvoluted mass spectrum of the biotinylated single-domain antibody against GST after overnight ligation. pelB-biotin: biotinylated sdAbaGST with pelB leader attached (calcd. mass $19879 \mathrm{Da}$ ); pelB: MESNA thioester of the sdAb-aGST with pelB leader attached (calcd. mass $19632 \mathrm{Da}$ ); pelB $\Delta$ 3-biotin: biotinylated sdAb-aGST with the first three amino acids of the pelB leader removed (calcd. mass $19457 \mathrm{Da}$ );); pelB $\Delta$ I 4-

biotin: biotinylated sdAb-aGST with the first 14 amino acids of the pelB leader removed (calcd. mass 18423

$\mathrm{Da}$ ); pelB $\Delta$ I 5-biotin: biotinylated sdAb-aGST with the first 15 amino acids of the pelB leader removed (calcd. mass I $8309 \mathrm{Da}$ ); pelB $\Delta$ I 6-biotin: biotinylated sdAb-aGST with the first 16 amino acids of the pelB leader removed (calcd. mass $18238 \mathrm{Da})$; 

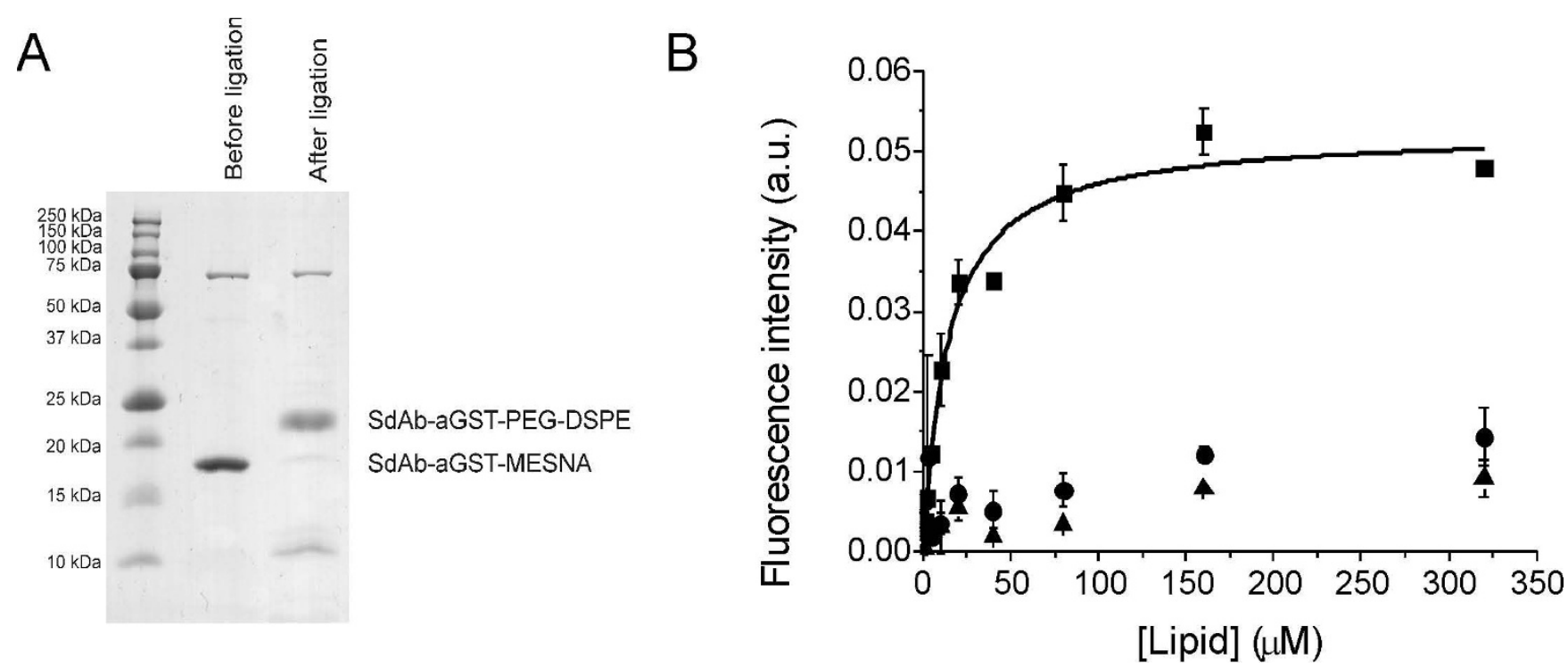

Figure 5

Preparation and activity analysis of single-domain antibody micelles. (A) SDS-PAGE analysis of NCL of $626 \mu M$ CysPEG-DSPE with $50 \mu \mathrm{M}$ sdAb-aGST-MESNA. The reaction was performed overnight at room temperature in buffer containing $100 \mathrm{mM}$ sodium phosphate, $50 \mathrm{mM}$ MPAA, $10 \mathrm{mM}$ TCEP, $\mathrm{pH}$ 6. (B) Solid-phase binding assay of sdAb-aGST functionalized micelles to GST (squares). Micelle binding was monitored by measuring the fluorescence of the rhodamine lipids at $620 \mathrm{~nm}$ using an excitation of $578 \mathrm{~nm}$. Control experiments using non-modified micelles incubated on GST (triangles) and sdAb-aGST functionalized micelles on milk powder coated plates (diamonds) are also shown for comparison. The solid line represents a fit to a I:I binding model using an apparent $K_{d}$ of $14 \mu \mathrm{M}$.

\section{Conclusion}

An efficient strategy was developed that generates active, folded single-domain antibodies with a reactive C-terminal thioester for direct application in nanoparticle functionalization via native chemical ligation. Two applications were reported here to illustrate their potential as generic building blocks for the generation of targeted nanoparticles, the generation of biotinylated singledomain antibodies and the efficient preparation of immunomicelles. Finally, the approach of targeting intein fusion proteins to the bacterial periplasm may provide a generic, attractive alternative to existing methods to obtain disulfide-containing proteins with a C-terminal thioester.

\section{Methods \\ General}

Unless stated otherwise, all reagents and chemicals were obtained from commercial sources and used without further purification. Cysteine-functionalized 1,2-Distearoylsn-glycero-3-phosphoethanolamine- $N$-[amino(poly(ethylene glycol))2000] (Cys-PEG-DSPE) was prepared according to a literature procedure [22]. The expression vectors PTXB1 and PTYB1, restriction enzymes and chitin beads were purchased from New England Biolabs (Beverly, MA). Competent cells were purchased from Novagen (Darmstadt, Germany). Monoclonal mouse anti-vsv glyc- oprotein antibody (V5507) was purchased from Sigma (St. Louis, MO). HRP-conjugated rabbit anti-mouse immunoglobulin polyclonal antibody (P0260) was purchased from DakoCytomation (Heverlee, The Netherlands). UV-Vis spectra were recorded on a Shimadzu Multispec 1501 spectrophotometer. Primers used for all the cloning procedures were supplied by MWG (Ebersberg, Germany).

\section{Plasmid constructs}

The GST-specific single-domain antibody was obtained from a naïve llama-derived nanobody library described previously [34]. Selection of phages for binding to bacterial expressed recombinant GST (pGEX-4T-2 vector) was performed essentially as described in $[35,36]$. The gene encoding for sdAb-aGST was amplified by PCR from vector pHENIX sdAb- $\alpha$ GST C11 with the primer pair pUC119pelB_f (5'-GGTGGTCATATGAAATACCTATTGCCTACGGCAGC-3') and pUC119vsv_r (5'-GGTGGTTGCTCTTCCGCATGCGGCCCCCTTTCCAAG-3'). The PCR products and the pTXB1 and pTYB1 vectors were doubledigested with the restriction endonucleases Nde I and Sap I followed by ligation of the amplified DNA fragments in the open plasmids yielding the expression plasmids pTXB1-sdAb-aGST and pTYB1-sdAb-aGST. DNA sequencing (BaseClear, Leiden, The Netherlands) using T7 promoter and intein-specific reversed primers (New England 
Biolabs) confirmed the correct in-frame fusion of the proteins with the intein sequence.

\section{Protein Expression and Purification}

The expression plasmids were transformed into E. coli BL21 (DE3) cells. Expression experiments were performed in $0.5 \mathrm{~L} \mathrm{LB}$ cultures supplemented with $100 \mu \mathrm{g} / \mathrm{mL}$ ampicillin by inoculating with a $5 \mathrm{~mL}$ overnight culture. The cultures were grown at $37^{\circ} \mathrm{C}$ and $250 \mathrm{rpm}$ until the $\mathrm{OD}_{600}$ reached a value between $0.5-0.6$. Protein expression was induced with $0.2 \mathrm{mM}$ IPTG and cultures were incubated for 3 hours at $30^{\circ} \mathrm{C}$. Cells were harvested by centrifugation for $10 \mathrm{~min}$ at $8,000 \mathrm{~g}$ at $4{ }^{\circ} \mathrm{C}$, after which the medium was discarded and the cell pellets were resuspended in 85 mL TES (30 mM Tris-HCl pH 8.0, 1 mM EDTA, 20\% (w/ v) sucrose) and incubated at room temperature for 10 minutes with continuous shaking. After centrifugation for $10 \mathrm{~min}$ at $8,000 \mathrm{~g}$ and $4{ }^{\circ} \mathrm{C}$, the pellet was resuspended in $85 \mathrm{~mL}$ of ice-cold $5 \mathrm{mM} \mathrm{MgSO}_{4}$ and incubated on ice for 10 minutes with occasional shaking. After centrifugation for $10 \mathrm{~min}$ at $8,000 \mathrm{~g}$ at $4^{\circ} \mathrm{C}, 2 \mathrm{~mL} 0.5 \mathrm{M}$ Tris-HCl pH 7.5 was added to the supernatant. ATP $(3 \mathrm{mM})$ was added to the supernatant and incubated for $1-3$ hours at $4{ }^{\circ} \mathrm{C}$ to suppress binding of DnaK to the sdAb-aGST intein fusion protein. The periplasmic protein fraction was directly applied to a chitin column that was equilibrated with 10 column volumes of column buffer $(20 \mathrm{mM}$ sodium phosphate, $0.1 \mathrm{mM}$ EDTA, $0.5 \mathrm{M} \mathrm{NaCl}, 3 \mathrm{mM}$ ATP, $\mathrm{pH}$ 8). The column was washed with 10 volumes of column buffer after which the columns were quickly flushed with 3 column volumes of cleavage buffer $(20 \mathrm{mM}$ sodium phosphate, $0.1 \mathrm{mM}$ EDTA, $0.5 \mathrm{M} \mathrm{NaCl}, 100 \mathrm{mM}$ MESNA, pH 6 ) and incubated overnight at $4{ }^{\circ} \mathrm{C}$. Proteins were eluted in cleavage buffer without MESNA and pooled. The protein concentration was determined by UV-Vis using $\varepsilon_{280}$ $\mathrm{nm}=24,535 \mathrm{M}^{-1} \mathrm{~cm}^{-1}$ or using a Quant-it protein assay (Invitrogen) according to the manufacturers instructions.

\section{LC-MS}

Samples for LC-MS analysis were concentrated with Biomax centrifugation filters (MWCO $5 \mathrm{kDa}$ ) for small volumes and Amicon centrifugational filters (MWCO 10 $\mathrm{kDa}$ ) for large volumes. Samples were buffer exchanged to a mixture of 9:1 $\mathrm{H}_{2} \mathrm{O}$ /acetonitrile or to $50 \mathrm{mM}$ ammonium acetate $\mathrm{pH}$ 6.8. Reversed phase HPLC was performed on a Vydac protein column with a mobile phase of $\mathrm{H}_{2} \mathrm{O}$ /acetonitrile with $0.1 \%$ TFA. ESI-MS spectra were measured on a Thermo Finnigan LCQ Deca XP MAX in positive mode. MagTran software was used for deconvolution.

\section{ELISA}

All washing steps were performed with $200 \mu \mathrm{l}$ MPBST (5\% milk powder, $0.05 \%$ Tween 20 in PBS $(137 \mathrm{mM} \mathrm{NaCl}, 2.7$ $\mathrm{mM} \mathrm{KCl}, 4.3 \mathrm{mM} \mathrm{Na}_{2} \mathrm{HPO}_{4}, 1.4 \mathrm{mM} \mathrm{KH} \mathrm{PO}_{4}$ pH 7.4)) unless stated otherwise. 96 wells Corning EIA/RIA Microplates were coated overnight at $4{ }^{\circ} \mathrm{C}$ with $0.5 \mu \mathrm{g} /$ well $(50$ $\mu \mathrm{l}) \mathrm{GST}$ or BSA in $0.1 \mathrm{M} \mathrm{NaHCO}_{3} \mathrm{pH}$ 8.6. After overnight incubation the plates were washed 3 times with PBS/ $0.05 \%$ Tween 20 . Plates were blocked with $50 \mu \mathrm{l}$ MPBST for 1 hour at room temperature. After washing the plates 3 times, $50 \mu \mathrm{l}$ samples of sdAb-aGST-MESNA were loaded and incubated for 1 hour at room temperature. Plates were washed 6 times and subsequently incubated with 50 $\mu \mathrm{l}$ mouse Anti-VSV monoclonal antibody (5000× diluted) for 1 hour. Plates were washed 6 times and subsequently incubated with $50 \mu \mathrm{l}$ alkaline HRP-conjugated rabbit antimouse immunoglobulin polyclonal antibody (2500x diluted), for 1 hour. Plates were washed 6 times and subsequently incubated with $50 \mu \mathrm{l} /$ well detection solution (1:1 peroxide buffer (UP)/Tetramethylbenzidine (TMB), BioMérieux, Boxtel, The Netherlands). Reaction was stopped after 5 to $10 \mathrm{~min}$ with $50 \mu \mathrm{l} 2 \mathrm{M}$ sulfuric acid. The absorbance was measured at $450 \mathrm{~nm}$ in duplicate on a Thermo multiskan ascent platereader.

\section{Solid phase binding assay with immunomicelles}

All washing steps were performed with $200 \mu$ l HBS. 96 wells Corning EIA/RIA Microplates were coated overnight at $4{ }^{\circ} \mathrm{C}$ with $0.5 \mu \mathrm{g} /$ well $(50 \mu \mathrm{l})$ GST or milk powder in HBS (10 mM HEPES, $135 \mathrm{mM} \mathrm{NaCl}, \mathrm{pH}$ 7.4). After overnight incubation the plates were washed 3 times. Plates were blocked with $50 \mu \mathrm{l}$ MHBS (5\% milk powder in HBS) for 3 hours at room temperature. After washing the plates 3 times, $50 \mu \mathrm{l}$ samples of sdAb-aGST micelles were loaded and incubated for 4 hours at room temperature. Plates were washed 8 times after which the fluorescence of the rhodamine-containing micelles was measured in duplicate on a Thermo Fluoroskan Ascent FL plate reader (excitation at $578 \mathrm{~nm}$, emission at $620 \mathrm{~nm}$ ).

\section{Surface Plasmon Resonance}

Sensorgrams were obtained on a Biacore T100 (GE Healthcare) using a CM5 chip functionalized with GST using standard EDC/NHS protocols. All binding experiments were performed at $25^{\circ} \mathrm{C}$ using PBS with $0.05 \%$ Tween-20 (PBST) as running buffer at a flow rate of $30 \mu \mathrm{L} /$ min. Samples containing $0-500 \mathrm{nM}$ of sdAb-aGSTMESNA in PBST were injected on a CM5 chip functionalized with GST (160 RU immobilized) for $400 \mathrm{sec}$, followed by a 10 min dissociation phase. Regeneration of the chip was performed with a $30 \mathrm{~s}$ injection of $10 \mathrm{mM}$ $\mathrm{NaOH}$. Aspecific binding and buffer effects were taken into account by subtracting the simultaneous response from a reference surface functionalized with ethanolamine.

\section{Ligation of cysteine-functionalized biotin to sdAb-aGST} Cysteine-functionalized biotin was prepared according to a literature procedure and checked with NMR and LC-MS 
analysis [37]. A reaction mixture was prepared containing $7 \mu \mathrm{M}$ sdAb- $\alpha$ GST-MESNA in $20 \mathrm{mM}$ sodium phosphate, $0.1 \mathrm{mM}$ EDTA, $0.5 \mathrm{M} \mathrm{NaCl}, \mathrm{pH} 6$ to which $1 \mathrm{mM}$ cysteinefunctionalized biotin, $50 \mathrm{mM}$ MPAA and $10 \mathrm{mM}$ tris(2carboxyethyl) phosphine hydrochloride (TCEP) were added. The final $\mathrm{pH}$ of the reaction mixture was 5.5. The reaction was incubated overnight at $20^{\circ} \mathrm{C}$ and analyzed using LC-MS analysis.

Ligation of sdAb- $\alpha$ GST to cysteine-functionalized micelles A mixture of $97.5 \mathrm{~mol}$ percent Cys-PEG-DSPE and $2.5 \mathrm{~mol}$ percent rhodamine-DPPE in chloroform was placed in a vial. After chloroform evaporation the obtained lipid film was rehydrated in $0.1 \mathrm{M}$ sodium phosphate $\mathrm{pH} 8.5$ ([lipid] $=640 \mu \mathrm{M}$ ) with $50 \mathrm{mM}$ MPAA and $10 \mathrm{mM}$ TCEP, vortexed for $2 \mathrm{~min}$ followed by $5 \mathrm{~min}$ sonication. SdAbaGST-MESNA was added to a final concentration of 50 $\mu \mathrm{M}$ (final pH was 6.7). After overnight incubation at room temperature the protein micelles were analyzed using SDS-PAGE to check for complete conversion to the lipidated protein.

\section{Authors' contributions}

SWAR developed the new expression system for antibody fragments and wrote the manuscript. IvB synthesized cysteine-functionalized biotin and supervised part of the research. JMHR provided the pHENIX plasmid with the sdAb-aGST and helped with the experimental procedures concerning the single-domain antibodies. MM was responsible for the conceptual design of this project and contributed to the writing of the manuscript. All authors read and approved the final manuscript.

\section{Additional material}

\section{Additional file 1}

Supporting information. The binding of sdAb-aGST functionalized with cysteine to GST assayed using SPR (figure S1), and the DNA and protein sequence of the sdAb-aGST.

Click here for file

[http://www.biomedcentral.com/content/supplementary/14726750-9-66-S1.pdf]

\section{Acknowledgements}

The authors thank Danielle Hof for guidance during the initial expression experiments of the single-domain antibodies, SyMOChem (Eindhoven) for synthesizing the cysteine-functionalized phospholipid, and Bert Meijer for general support. This work was supported by an NWO VIDI grant 700.56.428 to M.M. and the BSIK program entitled Molecular Imaging of Ischemic Heart Disease (project number BSIK03033).

\section{References}

I. Wu AM, Senter PD: Arming antibodies: prospects and challenges for immunoconjugates. Nat Biotechnol 2005, 23:II37-I|46.
2. Fernandez LA: Prokaryotic expression of antibodies and affibodies. Curr Opin Biotechnol 2004, I 5:364-373.

3. Holliger P, Hudson PJ: Engineered antibody fragments and the rise of single domains. Nat Biotechnol 2005, 23: I I 26- I I 36.

4. Revets H, De Baetselier P, Muyldermans S: Nanobodies as novel agents for cancer therapy. Expert Opin Biol Ther 2005, 5: I I I-I 24.

5. Nobs L, Buchegger F, Gurny R, Allemann E: Current methods for attaching targeting ligands to liposomes and nanoparticles. J Pharm Sci 2004, 93:1980-1992.

6. Camarero JA, Kwon Y, Coleman MA: Chemoselective attachment of biologically active proteins to surfaces by expressed protein ligation and its application for "protein chip" fabrication. J Am Chem Soc 2004, I 26: I4730-|473I.

7. Kalia J, Abbott NL, Raines RT: General method for site-specific protein immobilization by staudinger ligation. Bioconjug Chem. 2007, I 8(4): 1064-1069.

8. Jonkheijm P, Weinrich D, Schröder H, Niemeyer CM, Waldmann H: Chemical strategies for generating protein biochips. Angew Chem Int Ed Engl. 2008, 47(50):9618-9647.

9. Lempens EH, Helms BA, Merkx M, Meijer EW: Efficient and chemoselective surface immobilization of proteins by using aniline-catalyzed oxime chemistry. ChemBioChem 2009, 10:658-662

10. Camarero JA: Recent developments in the site-specific immobilization of proteins onto solid supports. Biopolymers. 2008 90(3):450-458.

II. Kwon Y, Coleman MA, Camarero JA: Selective immobilization of proteins onto solid supports through split-intein-mediated protein trans-splicing. Angew Chem Int Ed Engl. 2006, 45( I I): I726-I729.

12. Helms B, Van Baal I, Merkx M, Meijer EW: Site-specific protein and peptide immobilization on a biosensor surface by pulsed native chemical ligation. ChemBioChem 2007, 8: I790-I794.

13. Watzke A, Kohn M, Gutierrez-Rodriguez M, Wacker R, Schroder H, Breinbauer R, Kuhlmann J, Alexandrov K, Niemeyer CM, Goody RS, et al: Site-selective protein immobilization by staudinger ligation. Angew Chem Int Ed Engl. 2006, 45(9):|408-|4I2.

14. Dirksen A, Dawson PE: Expanding the scope of chemoselective peptide ligations in chemical biology. Curr Opin Chem Biol 2008, I 2:760-766.

15. Scheck RA, Francis MB: Regioselective labeling of antibodies through N-terminal transamination. ACS Chem Biol 2007, 2:247-25I.

16. Wu P, Shui W, Carlson BL, Hu N, Rabuka D, Lee J, Bertozzi CR: Sitespecific chemical modification of recombinant proteins produced in mammalian cells by using the genetically encoded aldehyde tag. Proc Natl Acad Sci USA 2009, 106:3000-3005.

17. Scheck RA, Dedeo MT, lavarone AT, Francis MB: Optimization of a biomimetic transamination reaction. J Am Chem Soc 2008, I30: I 1762-I I770.

18. Rush JS, Bertozzi CR: New aldehyde tag sequences identified by screening formylglycine generating enzymes in vitro and in vivo. I Am Chem Soc 2008, I30: | 2240-|224|

19. Olschewski D, Becker CFW: Chemical synthesis and semisynthesis of membrane proteins. Mol BioSyst 2008, 4:733-740.

20. van Baal I, Malda H, Synowsky SA, van Dongen JL, Hackeng TM, Merkx $M$, Meijer EW: Multivalent peptide and protein dendrimers using native chemical ligation. Angew Chem Int Ed Engl. 2005, 44(32):5052-5057.

21. Grogan MJ, Kaizuka Y, Conrad RM, Groves JT, Bertozzi CR: Synthesis of lipidated green fluorescent protein and its incorporation in supported lipid bilayers. J Am Chem Soc 2005, 1 27:|4383-|4387.

22. Reulen SW, Brusselaars WW, Langereis S, Mulder WJ, Breurken M, Merkx M: Protein-liposome conjugates using cysteine-lipids and native chemical ligation. Bioconjug Chem. 2007, I 8(2):590-596.

23. Reulen SWA, Dankers PYW, Bomans PHH, Meijer EW, Merkx M: Collagen targeting using protein-functionalized micelles: the strength of multiple weak interactions. J Am Chem Soc 2009 , | 3 | :7304-73 | 2

24. Dawson PE, Muir TW, Clark-Lewis I, Kent SB: Synthesis of proteins by native chemical ligation. Science 1994, 266:776-779.

25. Muir TW, Sondhi D, Cole PA: Expressed protein ligation: a general method for protein engineering. Proc Natl Acad Sci USA 1998, 95:6705-6710. 
26. Sydor JR, Mariano M, Sideris S, Nock S: Establishment of inteinmediated protein ligation under denaturing conditions: $C$ terminal labeling of a single-chain antibody for biochip screening. Bioconjugate Chem 2002, |3:707-7|2.

27. Bastings MMC, van Baal I, Meijer EW, Merkx M: One-step refolding and purification of disulfide-containing proteins with a $C$-terminal MESNA thioester. BMC Biotechnol 2008, 8:.

28. Raats J, van Bree N, van Woezik J, Pruijn G: Generating recombinant anti-idiotypic antibodies for the detection of haptens in solution. J Immunoassay Immunochem 2003, 24: I I5-I46.

29. Hagihara $Y$, Matsuda $T$, Yumoto $N$ : Cellular quality control screening to identify amino acid pairs for substituting the disulfide bonds in immunoglobulin fold domains. J Biol Chem 2005, 280:24752-24758

30. Saerens D, Pellis M, Loris R, Pardon E, Dumoulin M, Matagne A, Wyns $\mathrm{L}$, Muyldermans S, Conrath K: Identification of a universal VHH framework to graft non-canonical antigen-binding loops of camel single-domain antibodies. I Mol Biol 2005, 352:597-607.

31. Bruser T, Deutzmann R, Dahl C: Evidence against the doublearginine motif as the only determinant for protein translocation by a novel Sec-independent pathway in Escherichia coli. FEMS Microbiol Lett 1998, 164:329-336.

32. Saerens D, Kinne J, Bosmans E, Wernery U, Muyldermans S, Conrath $\mathrm{K}$ : Single domain antibodies derived from dromedary lymph node and peripheral blood lymphocytes sensing conformational variants of prostate-specific antigen. J Biol Chem 2004, 279:51965-51972.

33. Ashok B, Arleth L, Hjelm RP, Rubinstein I, Onyuksel H: In vitro characterization of PEGylated phospholipid micelles for improved drug solubilization: effects of PEG chain length and PC incorporation. J Pharm Sci 2004, 93:2476-2487.

34. Roodink I, Raats J, Zwaag B van der, Verrijp K, Kusters B, van Bokhoven H, Linkels M, de Waal RMW, Leenders WPJ: Plexin DI expression is induced on tumor vasculature and tumor cells: A novel target for diagnosis and therapy? Cancer Res 2005, 65:8317-8323.

35. Hof D, Hoeke MO, Raats JM: Multiple-antigen immunization of chickens facilitates the generation of recombinant antibodies to autoantigens. Clin Exp Immunol 2008, I 5 I:367-377.

36. Raats JH, Wijnen EM, Pruijn GM, van den Hoogen FH, van Venrooi WJ: Recombinant human monoclonal autoantibodies specific for citrulline-containing peptides from phage display libraries derived from patients with rheumatoid arthritis. J Rheumatol 2003, 30:1696-171I.

37. Tolbert TJ, Wong C-H: Intein-mediated synthesis of proteins containing carbohydrates and other molecular probes. J Am Chem Soc 2000, I 22:542 I-5428.

Publish with Bio Med Central and every scientist can read your work free of charge

"BioMed Central will be the most significant development for disseminating the results of biomedical research in our lifetime. "

Sir Paul Nurse, Cancer Research UK

Your research papers will be:

- available free of charge to the entire biomedical community

- peer reviewed and published immediately upon acceptance

- cited in PubMed and archived on PubMed Central

- yours - you keep the copyright
BioMedcentral 